\title{
INFLUENCE OF TECHNOLOGICAL FACTORS ON FATIGUE PROPERTIES OF STEEL SHEETS
}

Treatment technology can influence the fatigue process positively or negatively. The paper analyzes the influence of cold levelling of strips from coils of steel grade E 700 TS $\left(R_{e}=700 \mathrm{MPa}\right)$ on the fatigue crack initiation and the fatigue limit under one-sided bending $(R=0.1)$. It indicates a positive effect on the above-mentioned characteristics if strips are loaded under one-sided bending from the side where residual compressive stress is formed during levelling.

By blasting a sheet made of steel grade 11 375.1, the fatigue limit under symmetrical flat bending was increased due to the hardening and formation of residual compressive stress. The paper also indicates risks connected with blasting, influencing the fatigue life.

Key words: Internal stress, steel sheets, levelling, blasting, mechanical properties, fatigue limit.

\section{Introduction}

The steel fatigue process is a function of a great number of external and internal factors, and their superposition significantly changes the fatigue resistance of material. The internal factors mainly include the structural state of material, which is given by the chemical composition and production technology of a product [1, 2, 11]. The relationship between the structure and mechanical properties have attracted a great attention, and the yield point $R_{e}$, at which macroscopic plastic deformation takes place, is often considered as a macroscopic characteristic of the structure [3, 4]. From the practical point of view, the fatigue limit of steels is expressed using the yield point or the tensile stress of material, $\sigma_{C}=k \cdot R_{m}$, while the material constant $\mathrm{k}$ usually decreases with the growing steel strength, i.e., generally said, it is again a function of the steel structure $[2,5]$.

The treatment technology of a product usually results in a change of the properties given by the original structure of steel. During the cold levelling of strips from coils, on the upper side of the coil tensile stress and on the lower side compressive stress are formed, which significantly influence the initiation of fatigue damage and hence the service life of a product [6, 7]. During the surface treatment of a steel strip by blasting, compressive stress is also formed in the surface layer and tensile stress below this layer, while the deformation hardening of the surface layer and a change of the surface roughness take place. Some of the mentioned changes of the state decelerate (compressive stress, strain hardening) and others accelerate (increased roughness, tension stress below the strain-hardened layer) the fatigue process $[8,9]$. It results from the above-mentioned that from the viewpoint of the fatigue life it is necessary to utilize their favourable effect in the production technology.

The paper aims to analyse the influence of residual stress after the cold levelling of steel strips, as well as the influence of blasting on the fatigue life, since flat products are mainly loaded by variable loading, during which material fatigue takes place.

\section{Experiments and their analysis}

Residual stress influences the fatigue properties of steel strips with higher yield points more intensively. Therefore the experiments were carried out on a strip, $8 \mathrm{~mm}$ thick, made of microalloyed steel E 7000TS. The surface treatment by blasting is usually carried out on steel sheets with higher plasticity, and for experiments was used $3 \mathrm{~mm}$ thick steel sheet made of 11375.1 steel.

The structure of the microalloyed steel strip $(\mathrm{C}=0.08 \%$, $\mathrm{Mn}=1.80 \%, \mathrm{Si}=0.41 \%, \mathrm{Al}=0.016 \%, \mathrm{Mo}=0.16 \%, \mathrm{Nb}=0.46 \%$, $\mathrm{Ti}=0.16 \%, \mathrm{~V}=0.012 \%, \mathrm{Zr}=0.057 \%-$ wt. $\%$ ) after controlled rolling is non-polyedric, formed by acicular ferrite, bainite and precipitates of microalloying elements. The structure of the steel strip made of 11375.1 steel was ferritic-pearlitic, with the ferrite grain size of cca $0.012 \mathrm{~mm}$, corresponding to the carbon content of $0.15 \%$. The basic mechanical properties of the tested sheets are shown in Tab. 1.

Basic mechanical properties of tested steel strips

Table 1.

\begin{tabular}{|l|c|c|c|c|}
\hline \multicolumn{1}{|c|}{ Steel } & $\begin{array}{c}\text { Thickness } \\
{[\mathrm{mm}]}\end{array}$ & $\begin{array}{c}R_{e} \\
{[\mathrm{MPa}]}\end{array}$ & $\begin{array}{c}R_{m} \\
{[\mathrm{MPa}]}\end{array}$ & $\begin{array}{c}\mathrm{A}_{5} \\
{[\%]}\end{array}$ \\
\hline E 7000TS & 8 & 703 & 832 & 20.4 \\
\hline 11375.1 & 3 & 208 & 400 & 32.0 \\
\hline
\end{tabular}

After the cold levelling of the coil, residual tensile stress is formed on the upper side of the strip and residual compressive stress is formed on its lower side, as shown in Fig. 1. Using the tensometric residual stress measuring method, stress in the amount

\footnotetext{
* Marián Buršák ${ }^{1}$, Otakar Bokůvka ${ }^{2}$

${ }^{1}$ Faculty of Metallurgy, Technical University of Košice, Letná 9, 04200 Košice, Slovakia, E-mail: Marian.Bursak@tuke.sk

${ }^{2}$ Faculty of Mechanical Engineering, University of Zilina, Univerzitná 1, 01026 Zilina, E-mail: Otakar.Bokuvka@fstroj.utc.sk
} 
of cca $120 \mathrm{MPa}$ was measured in the depth of $0.5 \mathrm{~mm}$ on the upper side of the strip and cca $70 \mathrm{MPa}$ in the depth of $4 \mathrm{~mm}$ [10]. Test samples were taken from the strips in the rolling direction and notched test bars were made for fatigue tests (Fig. 2). The influence of residual stress on the fatigue crack initiation and the fatigue limit was tested under one-sided bending, with the asymmetry coefficient $R=0.1$

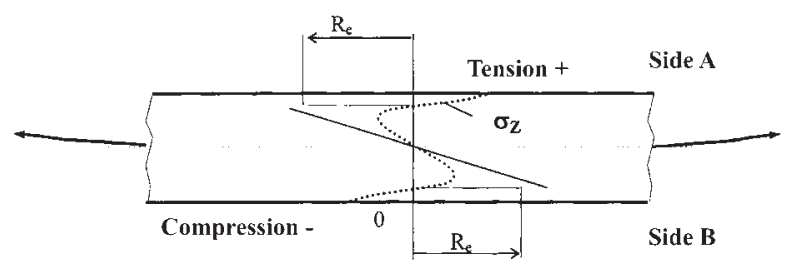

Fig. 1 Distribution of residual stress $\sigma_{z}$ after levelling a coil

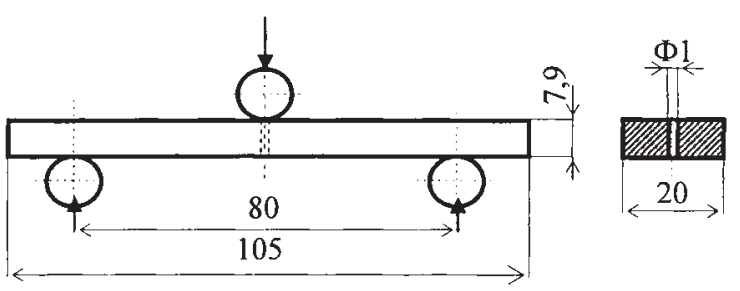

Fig. 2 Fatigue test bars made of E 700 TS steel strip

Test samples were taken in the rolling direction from the strips made of 11375.1 steel and test bars were made for fatigue bending tests (Fig. 3). Some of these test bars were blasted on all the sides with steel granulate with the size of $0.9 \mathrm{~mm}$ under the impact angle of $75^{\circ}$ and the pressure of $0.5 \mathrm{MPa}$. The result of blasting was surface strain hardening to the depth of $0.05 \mathrm{~mm}$, while the microhardness close to the surface $(0.01 \mathrm{~mm})$ increased

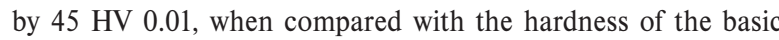
material. Because of the thickness of the hardened layer, the X-ray diffraction method was used to determine residual stress in this layer. Using this method it was found out that before blasting the sample had tension stress on the surface (cca $79 \mathrm{MPa}$ ) and after blasting it had residual compressive stress of as many as $293 \mathrm{MPa}$. The blasting resulted in an increased roughness of the test bars. The ground test bars had the mean arithmetic deviation $R_{a}=0.27 \mu \mathrm{m}$ and the highest profile height $R_{z}=1.56 \mu \mathrm{m}$, and the blasted test bars had $R_{a}=9 \mu \mathrm{m}$ and $R_{z}=45 \mu \mathrm{m}$. Such prepared test bars

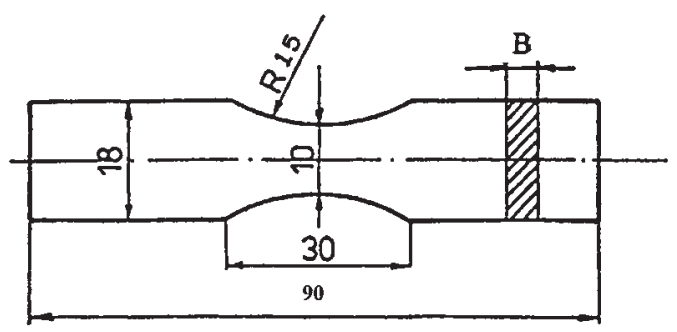

Fig. 3 Fatigue test bars made of 11375.1 steel strip were fatigue-tested under flat bending with the symmetric cycle $(R=-1)$.

The results of the fatigue crack initiation and growth tests on notched bars (Fig. 2) are shown in Fig. 4. The bars were loaded under one-sided bending, with the upper stress levels from 700 to $550 \mathrm{MPa}$. The documented results indicate that when the test bar was loaded under one-sided bending on the upper side (designation A), the crack initiation period was significantly shorter comparing to the test bar loaded on the lower side (designation B). For example, at the stress of $700 \mathrm{MPa}$ a crack $1 \mathrm{~mm}$ long is formed under loading on the side A after 54.000 cycles and on the side B after 107.000 cycles. This indicates an adverse effect of residual tension stress on the fatigue crack initiation.

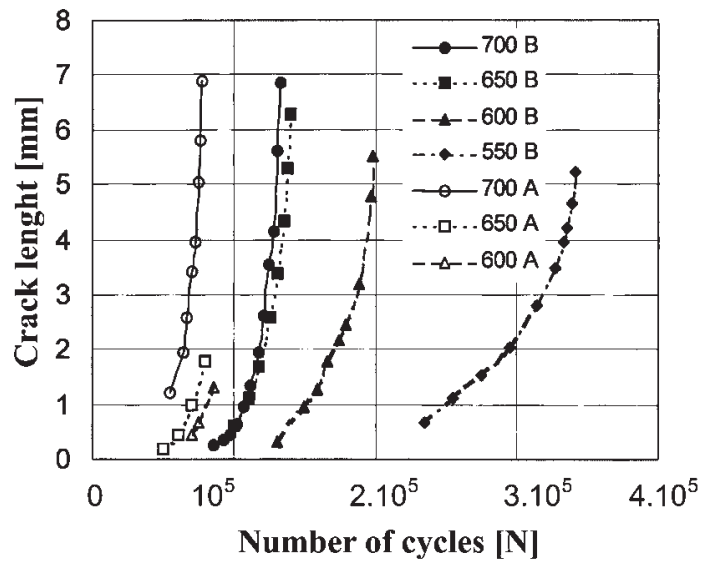

Fig. 4 Fatigue crack growth dependence on the number of cycles in E 700 TS steel at the stress of 700, 650,600 and $550 \mathrm{MPa}$. $A$ - Bending on the upper strip side, $B$ - Bending on the lower strip side

Residual stress also influences the fatigue limit values, similarly as the fatigue crack initiation. Fig. 5 presents Wöhler curves, obtained on notched bars under one-sided bending on the upper

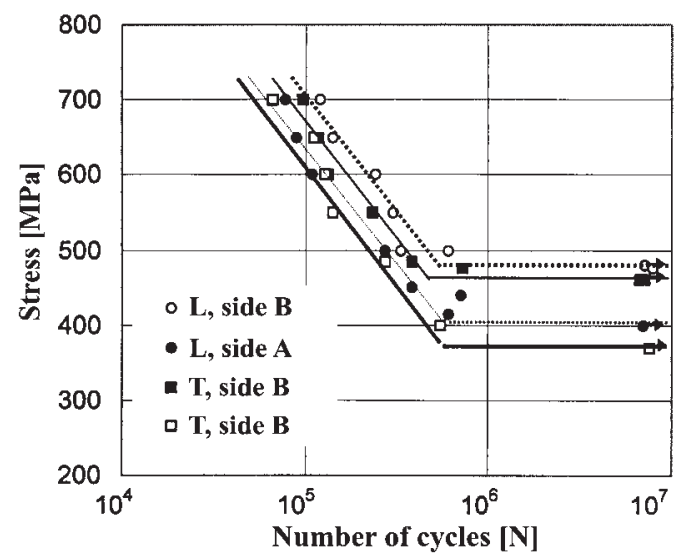

Fig. 5 Wöhler curves of $E 700$ TS steel for notched bars under one-sided bending $(R=0.1), L$ - rolling direction, $T$ - transversal direction, $A$ Bending on the upper strip side, $B$ - Bending on the lower strip side 
side (A) and the lower side (B). The number of cycles to failure in the oblique section of the curve, as well as the value of the fatigue limit under bending $\sigma_{\mathrm{Co}}$ for $7.10^{6}$ cycles, are lower in case of loading the bars on the upper side of the strip (A). The orientation of the bar with regard to the rolling direction has also a slight effect. The values of the fatigue limit under bending are lower in the transversal direction (T) than in the rolling (longitudinal) direction (L). This is, besides the structure, also caused by different values of residual stress in the $\mathrm{L}$ and $\mathrm{T}$ directions; residual stress is lower in the $\mathrm{T}$ direction. These facts could be utilized in practice, for example in the manufacture of flat products and their expected loading (containers, vehicles, etc.).

The experimental results of the influence of the blasted layer on the fatigue properties of the tested steel sheet are shown as Wöhler curves in Fig. 6. The fatigue limit of the blasted bars $\left(\sigma_{C o}= \pm 196 \mathrm{MPa}\right)$ is higher than the fatigue limit of the ground bars $\left(\sigma_{C o}= \pm 176 \mathrm{MPa}\right)$ by $11 \%$, which generally applies in the area of the time fatigue limit under bending. The above-mentioned indicates a clear positive effect of blasting on the fatigue properties, which is a result of strain hardening and residual compressive stress in the blasted layer.

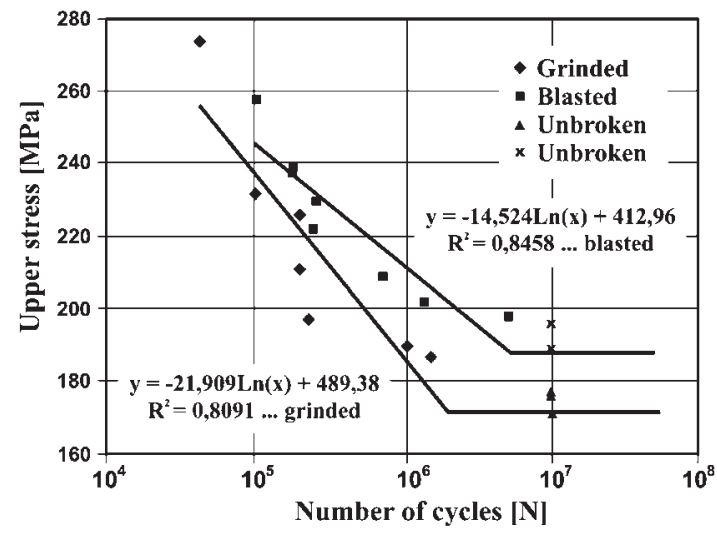

Fig. 6 Wöhler curves of steel grade 11375.1 under flat bending

$$
(R=-1)
$$

The analysis of the distribution of residual stress in the blasted layer (Fig. 7) also indicates certain risks, arising from the positive influence of blasting on the fatigue properties. Below the strainhardened layer, residual tension stress is formed, which negatively influences the fatigue properties. Significantly increased surface roughness has also an adverse effect. In case of overloading (Fig. 6 at $260 \mathrm{MPa}$ ), the favourable effect of blasting is lost and French defect band of the blasted bars is obviously extended, which may result in a fatigue fracture at a lower stress than the experimentally determined $\sigma_{C o}$ of the blasted bars.

Another risk of the decrease of fatigue resistance of blasted bars is shown by the results of the $\sigma-N$ relationship, processed using non-linear regression, which also takes into account fatigue tests where the test bar did not fail [11]. Such results processed as the $\sigma-N$ relationship are shown in Fig. 8. The fatigue limits at $10^{7}$ cycles are comparable with the results obtained from Wöhler curve

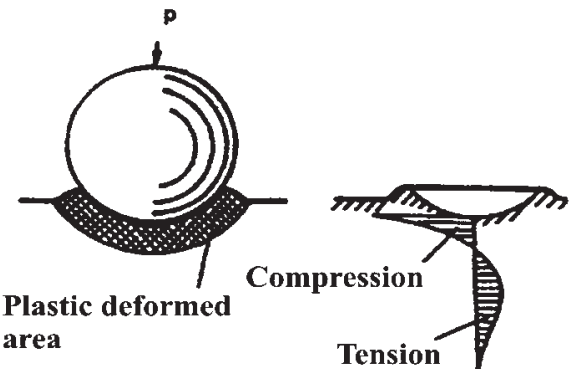

Fig. 7 Scheme of distribution of residual stress after blasting

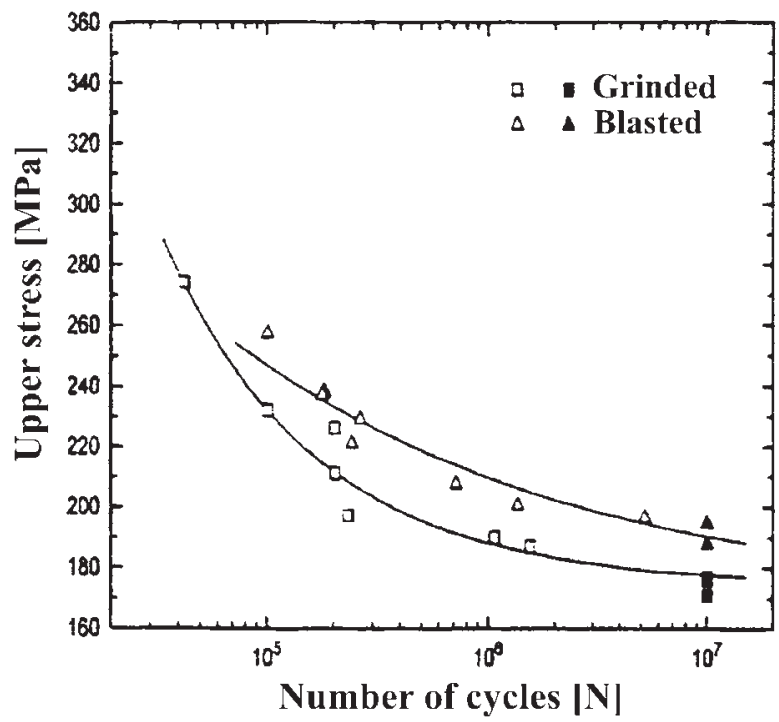

Fig. 8. Wöhler curves of 11375.1 steel under flat bending, determined by non-linear regression analysis

(Fig. 6). For the ground bars $\sigma_{C}= \pm 178 \pm 3 \mathrm{MPa}$, and for the blasted bars $\sigma_{C}= \pm 192 \pm 3 \mathrm{MPa}$. It results from Fig. 8 that in the ground bars at $10^{7}$ cycles the saturation of fatigue damage takes place, but in the blasted bars a damage accumulation takes place even after this number of cycles, and a decrease of the fatigue limit can be expected at a higher number of cycles. The non-linear regression also enabled us to determine the fatigue limit at an infinite number of cycles, $\sigma_{\infty}$, and this theoretic value is $175 \pm 3 \mathrm{MPa}$ for ground bars, hence it practically does not differ from the $\sigma_{C o}$ value, but for blasted bars it is $169 \pm 15 \mathrm{MPa}$ and is lower than $\sigma_{C o}$, and has also a significant dispersion variance. In accordance with the pieces of knowledge from [9], can be assume that the initiation of the fatigue failure was not on the surface, but below the blasted layer, where residual tension stress occurs. Its propagation towards the surface is also supported by unevenness of the blasted sheet surface. This creates conditions for fatigue failures at stress lower than $\sigma_{C o}$.

Figs. 9 and 10 document the fracture surfaces of ground bars and blasted bars at different stress values, and hence cycles to failure. The fatigue fracture of ground bars is initiated and propagates on the whole surface of the bar, while in blasted bars the 


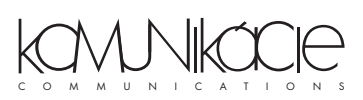

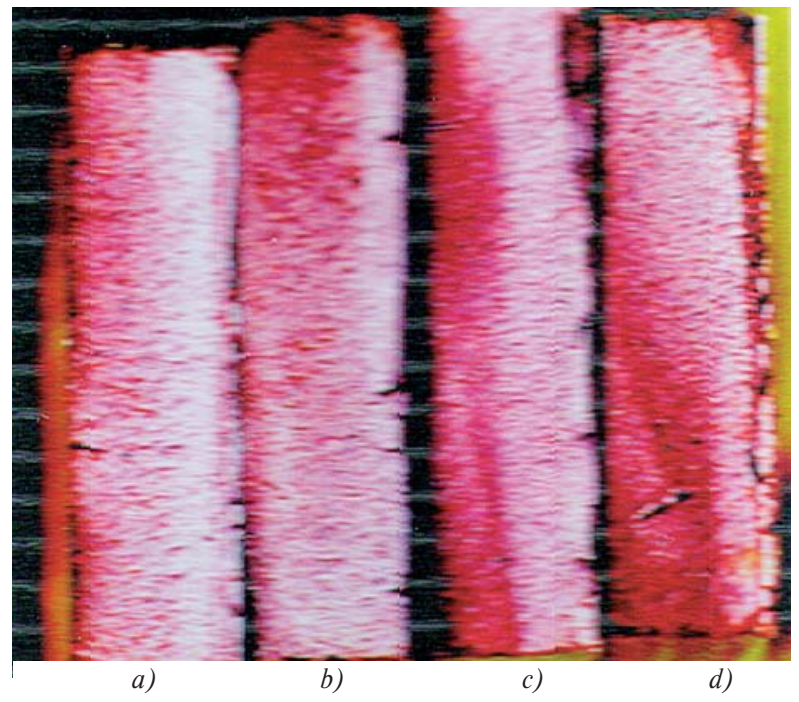

Fig. 9 Fracture surfaces of ground bars of made of steel grade 11375.1 under flat bending:

a) $\sigma=211 \mathrm{MPa}, N=202.600$ cycles, $b) \sigma=197 \mathrm{MPa}, N=232.900$ cycles, c) $\sigma=192 \mathrm{MPa}, N=944.000$ cycles, d) $\sigma=190 \mathrm{MPa}$, $N=1.070 .600$ cycles

fatigue fracture is initiated preferably in certain points of the surface, which indicates an adverse influence of roughness on the fatigue process. These pieces of knowledge should be considered in calculations of the fatigue life of components with a strain-hardened functional surface.

\section{Conclusion}

The paper analyses the influence of residual stress and surface strain hardening of steel sheets on fatigue properties under bending. After the cold levelling of $8 \mathrm{~mm}$ thick steel made of E 700TS steel, residual tension stress is formed on one side of the sheet and residual compressive stress on the other side. These types of stress influence the fatigue process in such a way that on the side of residual tension stress under one-sided bending $(R=0.1)$ the fatigue crack initiation starts at a significantly lower number of cycles and

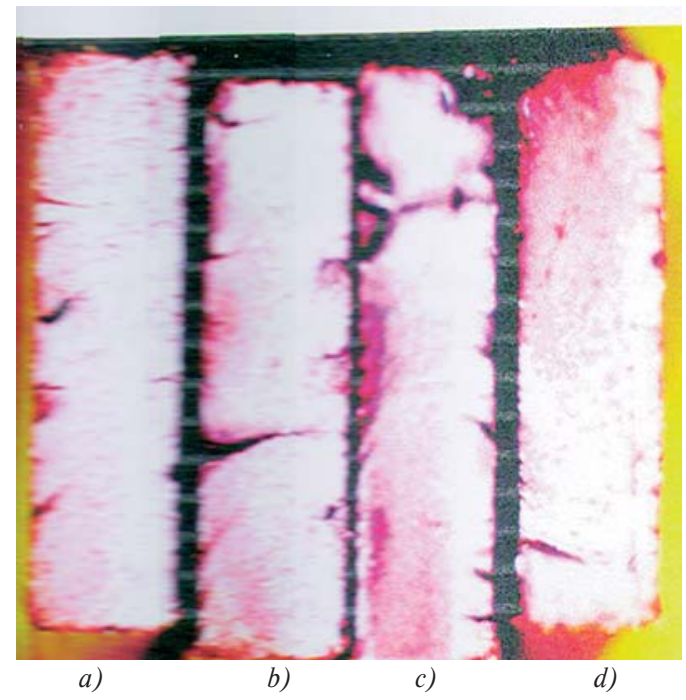

Fig. 10. Fracture surfaces of blasted bars made of steel 11375.1 under flat bending:

a) $\sigma=222 \mathrm{MPa}, N=246.200$ cycles, b) $\sigma=230 \mathrm{MPa}$, $N=268.600$ cycles, c) $\sigma=209 \mathrm{MPa}, N=733.100$ cycles, d) $\sigma=202 \mathrm{MPa}, N=1.405 .400$ cycles

the fatigue limit is also lower than in case of one-sided bending on the side with residual compressive stress.

The blasting of a $3 \mathrm{~mm}$ thick strip made of 11375.1 steel results in the strain hardening of the surface layer with the thickness of about $0.5 \mathrm{~mm}$, the formation of residual compressive stress, but also an increased surface roughness. The fatigue limit under symmetric bending at the number of cycles $10^{7}\left(\sigma_{C o}\right)$ is higher for blasted surfaces (by about $11 \%$ ) than for ground surfaces. It results from the analysis of fatigue tests that the theoretic fatigue limit (at an infinite number of cycles) of blasted sheets can also be at the same level or lower than that of ground sheets.

The presented results can be applied in practice when designing the production technology of flat products (orientation of the strip with regard to the loading method) and determining the fatigue life of strain hardened products.

\section{References}

[1] PUŠKÁR, A.: Limit States of Materials and Components (in Slovak), VEDA Bratislava, 1989

[2] TREBUŇA, F., BURŠÁK, M.: Limit States, Fractures (in Slovak), Grafotlač Prešov, 2002, ISBN 80-7165-362-4

[3] PARILÁK, L.: Structure Matter of Mechanical and Fracture Properties (in Slovak), HP, HF TU Košice, 1992

[4] ŠTEFAN, B.: Sheets Steel (in Slovak), 20, 1993, 16

[5] MICHEL, J., ČIŽMÁROVÁ, E., ORUŽINSKÁ, S.: Metallic Materials (in Slovak), 3, 1999, 191

[6] MACKINNON, J. A., POOK, L. P.: Experimental Techniques, September, 1987, 15

[7] PEŠEK, L.: Kovine, Zlitine, Technologije, 3, 1996, No 3-4, 185

[8] MIHALÍKOVÁ, M., KOVALOVÁ, K., MICHEL', J.: Materials Engineering (in Slovak), 11, 2004, 3, 13

[9] KOVALOVÁ, K., MAMUZIČ, I, BURŠÁK, M.: Metallurgy (in English), 43, 2004, 4, 335

[10] HIDVÉGHY, J., BURŠÁK, M., VRCHOVINSKÝ, V.: Acta Metallurgica Slovaca, 5, 1, 1999, 165

[11] HÍREŠ, O.: Physical Metallurgy of Steels and their Heat Treatment (in Slovak), GC TECH, Trenčín, 2006, ISBN 80-8075-099-8. 